\title{
The Effect of Kahoot Web-Based Learning on Learning Skills of Pharmacy Students: The Trend in Clinical Pharmacokinetics Course for 2 Generations
}

\author{
Karunrat Tewthanom \\ Faculty of Pharmacy, Silpakorn University, Nakhon Pathom, 73000, THAILAND.
}

\begin{abstract}
Background: Kahoot is a web-based learning that uses worldwide in the education field. From the review literature, lecture with a Kahoot web-based learning will improve the learning skill. However, there have been a few studies of using Kahoot web-based learning in pharmacy education. Therefore, the aim of this study is to compare pre-and post -learning skill using Kahoot web-based learning and observe the trend of effect for 2 generations. Method: Pre-and Posttest was established in Clinical Pharmacokinetics class of $5^{\text {th }}$ year Pharmacy Students for 2 consecutive generations. Before class, the students did the questionnaire to evaluate learning skill and then this group was beginning to enroll the class using Kahoot web-based learning. The 8 dimensions of learning skills; Literacy, Numeracy, Reasoning, Creative problem solving, Critical thinking, Collaborative, Communication and Computing were evaluated. The trend of effect was observed. Results: The data from 21 Pharmacy Students (11 from year 2016, 10 from year 2017) who enroll Clinical Pharmacokinetics course in topic "Therapeutic Drug Monitoring of Aminoglycosides" shown that improved of 8 dimension skills scores after learning with Kahoot web-based as follow (Mean \pm SD); Literacy (3.29 \pm 0.64 vs $4.19 \pm 0.40)$, Numeracy ( $3.24 \pm 0.83$ vs $4.05 \pm 0.50)$, Reasoning (3.29 \pm 0.56 vs $4.19 \pm 0.40$ ), Creative problem thinking $(3.05 \pm 0.59$ vs $4.19+0.60)$, Critical thinking $(3.10 \pm 0.70$ vs $4.10 \pm 0.62$ ), Collaborative (3.19 $\pm 0 . \overline{5}$ vs $4.19 \pm 0.40$ ), Communication (3.24 \pm 0.62 vs $4.24 \pm 0.44)$ and Computing (3.14 \pm 0.73 vs $4.00 \pm 0.62$ ). The separate analysis results had the same trends. Conclusion: From the results, Kahoot webbased leaning could improve learning skill in Pharmacy Students. The effects consist in 2 generations. However, the confirmation study in the large group also needed.
\end{abstract}

Key words: Kahoot, Web based learning, Learnings skill, Clinical Pharmacokinetic cause.

\section{INTRODUCTION}

Pharmacy education is now being changed by the current of social dynamic motivation. In the twenty -first century, the characteristic of the students are changed. The ideal characteristics of the students who will survival in twenty-first century have to get these basic 5 standard skills as follow; 1. Problem solving and decision making, 2. Creative and critical thinking, 3. Collaboration, communication and negotiation, 4. Intellectual curiosity and ability to find, select structure and evaluate information. 5. Motivation to be: an independent selfstarter, lifelong learners. ${ }^{1}$
Kahoot is the learning web based original from Norway. It is game-based learning that currently has more than 50 million users in 180 countries. The kahoot model is designed for use in classroom or other places with creating questions by anyone, any subjects and any ages of learners, since it can be able use by any device such as Lab-top Desktop

Clinical Pharmacokinetics is one of the difficult subject in pharmacy students' aspect. According to difficult content and many mathematic formulas, the most student or smartphone with internet access.
Submission Date: 04-07-2018; Revision Date: 24-10-2018; Accepted Date: 14-11-2018

DOI: 10.5530/ijper.53.2.28 Correspondence: Dr. Salih Ökten, Department of Maths and Science Education, Faculty of Education, Kırıkkale University, Yahşihan, Kırıkkale, TURKEY.

Phone: +90 3183574242 1394 E-mail: salihokten@kku. edu.tr

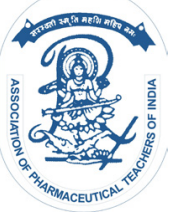

www.ijper.org 
complaint about learning this subject. With the proposed capacity of kahoot web-based learning, this study was aim to compare pre-and post -learning skill using Kahoot web based learning and observe the trend of effect for 2 generations.

\section{MATERIALS AND METHODS}

\section{Learners}

The $5^{\text {th }}$ year's pharmacy students, Faculty of Pharmacy, Silpakorn University in Academic year 2016 and 2017who were registered Clinical pharmacokinetics course.

\section{Process}

This study was performed in the routine topic "Therapeutic Drug Monitoring of Aminoglycosides" which contain for $2 \mathrm{~h}$. Before the class begin pre-test questionnaire with 5 Likert scales (score 1 to 5 ) for the 8 dimension skills (Literacy, Numeracy, Reasoning, Creative problem solving, Critical thinking, Collaborative, Communication and Computing) modified from the faculty of Education were distributed to 2 generations of the students (2016, 2017). During teaching of this topic in class, kahoot web-based learning was used. After the end of this topic in the class, post-test for 8 dimension skills were evaluated. This project was a routine work. The information and permission from the students were performed.

\section{Data Collection and Analysis}

The score of 8 dimensions skills were reported as the average calculated by Excel 2010. Dependent t-test was used for comparison of pre and post-test score. The level of significant $(\alpha)$ was 0.05 .

\section{RESULTS}

The data from 21 Pharmacy Students (11 from year 2016, 10 from year 2017 ) who enroll Clinical Pharmacokinetics course in topic "Therapeutic Drug Monitoring of Aminoglycosides" shown that improved of 8 dimension skills scores after learning with Kahoot web-based as follow (Mean \pm SD); Literacy (3.29 \pm 0.64 vs $4.19 \pm 0.40)$, Numeracy(3.24 \pm 0.83 vs $4.05 \pm 0.50)$, Reasoning (3.29 \pm 0.56 vs $4.19 \pm 0.40)$, Creative problem thinking $(3.05 \pm 0.59$ vs $4.19 \pm 0.60)$, Critical thinking(3.10 \pm 0.70 vs $4.10 \pm 0.62)$, Collaborative (3.19 \pm 0.75 vs $4.19 \pm 0.40)$, Communication (3.24 \pm 0.62 vs $4.24 \pm 0.44)$ and Computing (3.14 \pm 0.73 vs $4.00 \pm 0.62)$. In pool data of 2 generations and for generation year 2017, All dimensions had significant increase $(p<005)$. The results are demonstrated in Figure 1, Figure 2, Table 1 and Table 2, respectively.

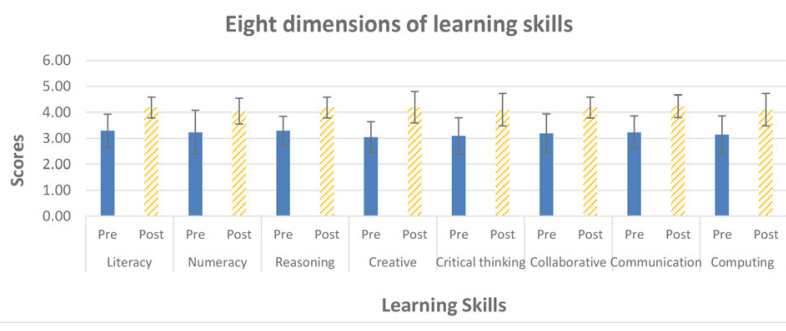

Figure 1: The comparison of eight dimensions of learning skill between pre-testand post-test questionnaires.

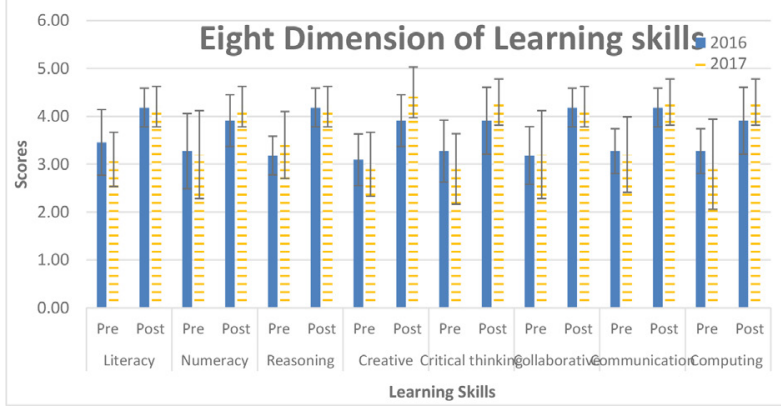

Figure 2: The comparison of eight dimensions of learning skill between pre-test and post-test questionnaire; the trends for 2 generations (2016 vs 2017).

\begin{tabular}{|c|c|c|c|c|c|c|}
\hline \multirow[t]{2}{*}{ Dimensions } & \multicolumn{3}{|c|}{ Score 2016 (Mean+ SD) N=11 } & \multicolumn{3}{|c|}{ Score 2017 (Mean+ SD) N=10 } \\
\hline & Pre & post & $p$-value & Pre & post & $p$-value \\
\hline Literacy & $3.45 \pm 0.69$ & $4.18 \pm 0.40$ & $0.039^{*}$ & $3.10 \pm 0.57$ & $4.20 \pm 0.42$ & $0.00017^{*}$ \\
\hline Numeracy & $3.27 \pm 0.79$ & $3.91 \pm 0.54$ & 0.066 & $3.20 \pm 0.92$ & $4.20 \pm 0.42$ & $0.0084^{*}$ \\
\hline Reasoning & $3.18 \pm 0.40$ & $4.18 \pm 0.40$ & $0.0003^{*}$ & $3.40 \pm 0.70$ & $4.20 \pm 0.42$ & $0.0031^{*}$ \\
\hline Creative & $3.09 \pm 0.54$ & $3.91 \pm 0.54$ & $0.0011^{*}$ & $3.45 \pm 0.69$ & $4.50 \pm 0.53$ & $0.00008^{*}$ \\
\hline Critical thinking & $3.27 \pm 0.65$ & $3.91 \pm 0.70$ & 0.088 & $2.90 \pm 0.74$ & $4.30 \pm 0.48$ & $0.001^{*}$ \\
\hline Collaborative & $3.18 \pm 0.60$ & $4.18 \pm 0.40$ & $0.001^{*}$ & $3.20 \pm 0.92$ & $4.20 \pm 0.42$ & $0.008^{*}$ \\
\hline Communication & $3.27 \pm 0.47$ & $4.18 \pm 0.40$ & $0.0002^{*}$ & $3.20 \pm 0.79$ & $4.30 \pm 0.48$ & $0.001^{*}$ \\
\hline Computing & $3.27 \pm 0.47$ & $3.91 \pm 0.70$ & $0.010^{*}$ & $3.00 \pm 0.94$ & $4.30 \pm 0.48$ & $0.001^{*}$ \\
\hline
\end{tabular}

$* \mathrm{P}<0.05$ 


\begin{tabular}{|c|c|c|c|}
\hline \multirow{4}{*}{$\begin{array}{c}\text { Table 2: The eight dimension scores (Combination of } \\
\text { 2 generations } \\
(2016+2017))\end{array}$} \\
\hline \multirow{2}{*}{ Dimensions } & Score 2016+ 2017(Mean+ SD) N=21 \\
\cline { 2 - 4 } & Pre & post & p-value \\
\hline Literacy & $3.45 \pm 0.69$ & $4.18 \pm 0.40$ & $0.000001^{*}$ \\
\hline Numeracy & $3.45 \pm 0.69$ & $4.18 \pm 0.40$ & $0.0011^{*}$ \\
\hline Reasoning & $3.45 \pm 0.69$ & $4.18 \pm 0.40$ & $0.000001^{*}$ \\
\hline Creative & $3.45 \pm 0.69$ & $4.18 \pm 0.40$ & $0.0000005^{*}$ \\
\hline Critical thinking & $3.45 \pm 0.69$ & $4.18 \pm 0.40$ & $0.0004^{*}$ \\
\hline Collaborative & $3.45 \pm 0.69$ & $4.18 \pm 0.40$ & $0.00002^{*}$ \\
\hline Communication & $3.45 \pm 0.69$ & $4.18 \pm 0.40$ & $0.0000005^{*}$ \\
\hline Computing & $3.45 \pm 0.69$ & $4.18 \pm 0.40$ & $0.00006^{*}$ \\
\hline
\end{tabular}

$* \mathrm{P}<0.05$

\section{DISCUSSION}

From the results reveal that kahoot web-based leaning could improve learning skill significantly in Pharmacy Students. The several evidence also showed the same phenomenon. For example, in many fields such as physics, chemistry, engineering, computer sciences and medicine or pharmacy, the studies found that kahoot could create motivation of the students

This study, provided more information about effect of the 8 learning skills that similar to previous studies which evaluated only knowledge skill (literacy) $\cdot{ }^{1-5}$ Study of Micaela Esteves et al. supported about the advantages of kahoot web based learning. ${ }^{6}$ Consider about the consistency effect of kahoot web-based leaning, the second generation was tested in this study (Year 2017), It found the similar effect as same as previous generation of students (Year 2016). According to the structure of kahoot web-based that encourage learning skills, therefore, it can applied for the subject that need to simplify the content as clinical pharmacokinetics course.

\section{CONCLUSION}

From the results, Kahoot web-based leaning could improve learning skills in Pharmacy Students. The effects consist in 2 generations. However, the confirmation study in the large group also needed.

\section{ACKNOWLEDGEMENT}

The participation of fifth-year pharmacy the students in this study were appreciated. Thank you for all of the officers at the faculty who involve about the evaluation course process.

\section{AUTHOR CONTRIBUTIONS}

The author contribute to set the design activity, evaluation, interpretation and writing the manuscript for submission

\section{CONFLICT OF INTEREST}

The author declare no conflict of interest.

\section{REFERENCES}

1. Brauer AS. Use of Kahoot game for increased student motivation and ASEE Southeastern Section Conference. American Society for Engineering Education. 2018;6.

2. Greciano GC. Common misconception about psychopharmacology in undergaruate psychology and pharmacy students. The European Proceedings of Social and Behavioural Sciences. Future academay. 2018;5. from http://dx.doi.org/10.15405/epsbs.2017.10.75

3. Varannai I, Sasvári PL. The Use of Gamification in Higher Education: An Empirical Study. International Journal of Advanced Computer Science and Applications. 2017;8(10):6.

4. Meesook ST. Thailand's classroom learning practices in secondary level: Are we ready for. International Journal of Medicine and Medical Sciences. 2017;8(1):1-12.

5. Pop A. Designing an oline course: free educational tools for esp. Journal of Romanian Literatry Studies. 2017;(10):176-82.

6. Esteves MAP. The Use of New Learning Technologies in Higher. International Journal of Engineering Pedagogy. 2018;8(2):1-13.



\section{SUMMARY}

- The objectives of this study is to compare pre-and post -learning skill using Kahoot web-based learning and observe the trend of effect for 2 generations.

- From the pre-post-test of learning skill using Kahoot web-based learning in 21 Fifth years Pharmacy students (11 from year 2016, 10 from year 2017) who enroll Clinical Pharmacokinetics course in topic "Therapeutic Drug Monitoring of Aminoglycosides" shown that improved of 8 dimension skills scores (Literacy, Numeracy, Reasoning, Creative problem solving, Critical thinking, Collaborative, Communication and Computing) after learning with Kahoot web-based.

- It can be suggested that Kahoot web-based leaning could improve learning skills in Pharmacy Students. The effects consist in 2 generations. However, the confirmation study in the large group also needed.

Cite this article: Tewthanom K. The Effect of Kahoot Web-Based Learning on Learning Skills of Pharmacy Students: The Trend in Clinical Pharmacokinetics Course for 2 Generations. Indian J of Pharmaceutical Education and Research. 2019;53(2):212-5. 